Disease Focus

Editor's Note: Disease Focus articles provide brief overviews of a neural disease or syndrome, emphasizing potential links to basic neural mechanisms. They are presented in the hope of helping researchers identify clinical implications of their research. For more information, see http://www.jneurosci.org/misc/ifa_minireviews.dtl.

\title{
Neurobiology of Tourette Syndrome: Current Status and Need for Further Investigation
}

\author{
Ryan J. Felling and Harvey S. Singer \\ Department of Neurology, Division of Pediatric Neurology, Johns Hopkins University School of Medicine, Baltimore, Maryland 21287
}

Tourette syndrome (TS) is a common, chronic neuropsychiatric disorder characterized by the presence of fluctuating motor and phonic tics. The typical age of onset is $\sim 5-7$ years, and the majority of children improve by their late teens or early adulthood. Affected individuals are at increased risk for the development of various comorbid conditions, such as obsessive-compulsive disorder, attention deficit hyperactivity disorder, school problems, depression, and anxiety. There is no cure for tics, and symptomatic therapy includes behavioral and pharmacological approaches. Evidence supports TS being an inherited disorder; however, the precise genetic abnormality remains unknown. Pathologic involvement of cortico-striatal-thalamo-cortical (CSTC) pathways is supported by neurophysiological, brain imaging, and postmortem studies, but results are often confounded by small numbers, age differences, severity of symptoms, comorbidity, use of pharmacotherapy, and other factors. The primary site of abnormality remains controversial. Although numerous neurotransmitters participate in the transmission of messages through CSTC circuits, a dopaminergic dysfunction is considered a leading candidate. Several animal models have been used to study behaviors similar to tics as well as to pursue potential pathophysiological deficits. TS is a complex disorder with features overlapping a variety of scientific fields. Despite description of this syndrome in the late 19th century, there remain numerous unanswered neurobiological questions.

In the 1880's, Georges Gilles de la Tourette published a two-part article in which he emphasized differences between tics and chorea. Although many of the descriptions about the disorder, which now bears his name [Tourette syndrome (TS)], have been revised, his belief that tics are a neurological movement disorder and not a psychiatric condition persists to the present (Goetz and Klawans, 1982). Nevertheless, despite multiple advances and widespread acceptance of TS being a biological disorder, the precise etiology and underlying pathophysiological mechanisms remain unknown. The goals of the present review are to briefly describe the clinical phenomenology of TS and related

Received Jan. 10, 2011; revised June 7, 2011; accepted July 8, 2011.

Correspondence should be addressed to Dr. Harvey S. Singer, Division of Pediatric Neurology, Johns Hopkins Hospital, Rubenstein Child Health Building, 200 North Wolfe Street, Suite 2158, Baltimore, MD 21287. E-mail: hsinger@jhmi.edu.

DOI:10.1523/JNEUROSCI.0150-11.2011

Copyright $\odot 2011$ the authors $\quad 0270-6474 / 11 / 3112387-09 \$ 15.00 / 0$ tic disorders, to review current information on genetic and neurobiological mechanisms, and to identify areas in need of further investigation.

\section{The Clinical Problem}

The hallmark of TS is the presence of chronic, fluctuating motor and vocal tics. Best diagnosed by observation, tics are sudden, repetitive, involuntary movements or vocalizations with differing degrees of intensity and frequency, and unpredictable durations (Kurlan, 2010). Tics are currently classified as motor or vocal (phonic), although this separation has been questioned, and further subclassified into simple or complex categories. Simple tics generally involve fewer muscle groups, are briefer in duration, and tend to be more meaningless in their appearance/phonation. Common examples of simple tics are as follows: motor: eye blinking, head jerking, facial grimacing, or shoulder shrugging; and phonic: sounds or noises such as throat clearing, sniffing, or grunting. In contrast, complex tics typically involve more elaborate manifestations and appear to have a more purposeful action or verbalization. Examples of common complex tics are as follows: motor: touching objects, clapping, obscene gestures, or body contortions; and phonic: the repetition of words including echolalia, palilalia, and coprolalia. Characteristics that help to differentiate tics from other paroxysmal movement disorders include a waxing and waning course, the presence of particular factors that exacerbate (stress, anxiety, fatigue) or reduce (concentrating or focusing) symptoms, a suggestible nature, the presence of a premonitory sensation, and brief suppressibility.

Tics are common in childhood, with epidemiological studies showing that $\sim 20$ $30 \%$ of children exhibit brief, repetitive, involuntary movements or sounds in a classroom setting (Kurlan et al., 2001). The diagnosis of a tic disorder is based solely on 
historical features and a clinical examination that confirms their presence and eliminates other etiological conditions. There is no reliable diagnostic test for TS or the spectrum of disorders that have tics as their cardinal feature. The formal criteria for TS require an age of onset before 18 years, the presence of multiple motor and at least one vocal tic (not necessarily concurrently), a waxing and waning course, the addition and subtraction of various tics, the presence of tic symptoms for at least 1 year, and the absence of a precipitating illness (e.g., encephalitis, stroke, or degenerative disease) or tic-inducing medication. Motor tics have a typical age of onset of $\sim 5-7$ years, and the course of TS can be quite variable. Most patients, however, have a decline in symptoms during the adolescence or early adulthood (Leckman et al., 1998; Bloch et al., 2006), leading to suggestions of a developmental disorder. In addition to tics, children with TS often have a variety of comorbid psychopathologies, including attention deficit hyperactivity disorder (ADHD), obsessivecompulsive disorder (OCD), learning difficulties, sleep abnormalities, anxiety, and other behaviors, all of which can have a significant impact on the individual's prognosis (Channon et al., 2003; Sukhodolsky et al., 2003; Cavanna et al., 2009). The frequent occurrence of ADHD and OCD in affected individuals has led to suggestions of overlapping pathophysiology between tic disorders and these conditions.

A discussion of treatment is beyond the scope of this review and has been described previously (Singer et al., 2010). In brief, there is no specific cure for tics. The indications for initiating tic-suppressing therapy include psychosocial problems, functional difficulties, disruptions in the academic or work environment, or physical discomfort. Available therapies include both behavioral (habit reversal, cognitive behavioral, and relaxation therapies) and pharmacological approaches. The beneficial response to medications affecting specific neurotransmitter systems is often used to support a pathological involvement, e.g., improvement of tics following the use of dopamine receptor antagonists.

\section{Etiology}

Numerous studies have confirmed Gilles de la Tourette's initial suspicion that tic disorders are inheritable, but the genetics underlying the disorders have proven complicated (State, 2010). Familial studies have repeatedly demonstrated significant increases in the incidence of TS or other tic disorders in first degree relatives of affected individuals (McMahon et al., 2003). Studies in twins also support a genetic disorder with a concordance of chronic tics in $77-94 \%$ of monozygotic compared to just $23 \%$ in dizygotic twins (Price et al., 1985; Hyde et al., 1992). Despite these reports, the precise pattern of transmission and the specific genes involved remain elusive. Linkage analyses have suggested several chromosomal locations, but without a clear reproducible locus (Pauls, 2006; O’Rourke et al., 2009). Similarly, candidate gene studies have failed to yield consistent results for specific susceptibility genes. Much attention has been paid to dopaminergic candidates, and there is evidence of a significant association between TS and a dopamine transporter polymorphism (DAT1 Ddel) (Yoon et al., 2007b). Several recent candidate genes have included: a heterozygous loss of function mutation in L-histidine decarboxylase, which encodes the rate limiting enzyme in histamine biosynthesis (Ercan-Sencicek et al., 2010); functional variations of the SLITRK1 gene, with homology to a known axon guidance molecule (Scharf et al., 2008); and DLGAP3, a postsynaptic scaffolding protein highly expressed in striatal glutamatergic synapses (Crane et al., 2011).

Multiple factors contribute to the ongoing difficulty in identifying a specific means of genetic transmission, including phenotypic heterogeneity, the variable expression of comorbid conditions, genomic imprinting [sex of the transmitting parent affecting clinical phenotype (Lichter et al., 1995; Eapen et al., 1997)], bilineal versus unilineal transmission (Hanna et al., 1999; Lichter et al., 1999), and epigenetic factors. Several studies have suggested that a variety of prenatal and perinatal risks may be associated with the subsequent development of TS, including the timing of perinatal care, severity of mother's prenatal nausea and vomiting, proband birth weight, the $5 \mathrm{~min}$ Apgar score, and prenatal maternal smoking (Leckman et al., 1990; Burd et al., 1999; Mathews et al., 2006; Young et al., 2008; Pringsheim et al., 2009). Further replication, however, is necessary before any significance can be attributed to these factors. The emergence of genomic methods that enable comprehensive investigation of both rare and common genetic variations and the availability of large patient cohorts is expected to provide valuable insights in the near future (Grados, 2010; State, 2010).

Another proposed theory is that tics can be an acquired consequence of autoimmune mechanisms following a Group A $\beta$-hemolytic streptococcal infection (GABHS) (Swedo et al., 1998; Snider and Swedo, 2003), a condition labeled as pediatric autoimmune neuropsychiatric disorder associated with a streptococcal infection (PANDAS). Indirect support of such a theory includes a significantly higher incidence of autoimmune disease in the mothers of children with tics (Murphy et al., 2010). Nevertheless, the existence of this etiological entity is extremely controversial based on both epidemiological and autoimmune studies (Kurlan, 1998, 2004; Singer and Loiselle, 2003; Kurlan and Kaplan, 2004; Singer et al., 2005b; Kurlan et al., 2008; Singer et al., 2008; Morris et al., 2009; Leckman et al., 2011).

\section{Neurobiology of TS \\ Circuits}

A series of parallel cortico-striatal-thalamocortical (CSTC) circuits that link specific regions of the frontal cortex to subcortical structures has provided a framework for understanding the interconnected neurobiological relationships that exist between TS and its multiple comorbid problems (Singer and Harris, 2006; Leckman et al., 2010; Mazzone et al., 2010). In classical models of movement disorders the basal ganglia was believed to influence behavior by changing cortical excitability through the interplay of the "direct" [striatum to globus pallidus interna (GPi)] and the multisynaptic "indirect" [striatum to globus pallidus externa (GPe) to subthalamic nucleus (STN) to GPi] pathway (Albin et al., 1989). According to this model, hyperkinetic disorders were the result of increased cortical excitability, due to either a reduction of direct pathway excitatory effect or an increase in the indirect inhibitory effect. Since this direct/indirect pathway approach failed to address the specificity of tics, other hypotheses have been developed that view the basal ganglia as performing a process of action selection, i.e., focused facilitation of selected movements and inhibition of competing motor patterns (Mink, 2003). Within this system, tics are viewed as a focal excitatory abnormality in the striatum that causes an erroneous inhibition of a group of neurons in the GPi and in turn a disinhibition of cortical neurons (Mink, 2001; Albin and Mink, 2006).

\section{Animal models}

Several animal models have been used to investigate TS on different bases: (1) face validity, i.e., behaviors or movements that have some characteristics resembling motor tics (e.g., motor stereotypies, sequential super-stereotypy, repetitive grooming, circling, and self injurious behaviors) (Dodman et al., 1994; Campbell et al., 2000; Berridge et al., 2005; Löscher, 2010; Taylor et al., 2010); or (2) construct validity, i.e., the 
animal model has a pathophysiological or developmental neural circuit deficit that is consistent with current knowledge concerning TS. Examples in this latter category include the following: a psychostimulantinduced model; the D1CT-7 transgenic and dopamine transporter knockdown (DATKD) mutant mice; a monkey model with striatal disinhibition-induced tics; and rodent models with immunologically related basal ganglia dysfunction.

\section{Psychostimulant model}

The psychostimulant model derives some relevance based on the ability of dopaminergic enhancing medications to exacerbate tics and stimulate locomotor behavior. This rodent model has provided important understandings about the role of the basal ganglia, especially striasomes, and the activation of stereotypic behaviors (Canales and Graybiel, 2000; Graybiel, 2000).

D1 receptor cholera toxin transgenic model The D1CT-7 transgenic mouse (produced using a transgene made by fusing the promoter region for the human D1 receptor with the intracellular A1 subunit of cholera toxin) clinically demonstrates compulsive behaviors (repetitive climbing, digging, and leaping), biting behaviors, and jerking movements (flurries of "twitches" of the head, limbs, and trunk) that begin as early as postnatal day 16 (Burton et al., 1991; Nordstrom and Burton, 2002). Jerky movements, similar to what occurs in TS, are reduced following treatment with clonidine and D2 antagonists. Animals have a reduced seizure threshold which is atypical for children with TS. The construct validity of this model for tics is based on hyperactivity within cortical, limbic, and corticostriatal circuitry, although its correlation to TS has been questioned (Swerdlow and Sutherland, 2005).

\section{DAT-KD mutant mouse}

The DAT-KD mouse has a markedly reduced expression of DAT in striatal dopamine neurons, and extracellular dopamine levels are $170 \%$ of wild-type controls (Zhuang et al., 2001). Behaviorally the animals are hyperactive and have perseverative behaviors and a pattern of more stereotyped and syntactic grooming sequences that resist disruption (Berridge et al., 2005). This model lacks tic-like jerking movements and is more consistent with obsessive-compulsive-like behaviors.

\section{Monkey focal striatal disinhibition}

In two cynomolgus monkeys, focal disinhibition of the sensorimotor putamen, using the $\mathrm{GABA}_{\mathrm{A}}$ antagonist bicuculline, produced repetitive motor tics predominantly in the orofacial region (McCairn et al., 2009). Local field potential spikes, which correlated with tics, were identified throughout the cortico-basal ganglia pathway. Results suggest that output nuclei of the basal ganglia provide a temporally exact and spatially distributed release signal, but that the final activation of tics likely occurs downstream from basal ganglia output.

\section{Autoimmune models}

Primarily two types of models have been used to investigate immune mechanisms in tic disorders.

Passive transfer of antibodies. This approach evaluates behavioral effects following the infusion of sera or IgG from individuals with TS into rodent striatum. Results remain very controversial. Some investigations have shown that sera from TS subjects produced a significant increase in stereotypic behaviors (e.g., licks and forepaw shakes) as well as episodic utterances (Hallett et al., 2000; Taylor et al., 2002; Liu et al., 2008). In marked contrast, other studies infusing TS or PANDAS sera at the same coordinates showed no significant increase in stereotypic behaviors and no rat developed any audible abnormality (Loiselle et al., 2004). Negative studies were also confirmed in a blinded, collaborative three-center effort involving several of the previously reporting institutions (Singer et al., 2005a).

Immunization with GABHS. This model evaluates the appearance of autoantibodies and behavioral effects following immunization of mice with GABHS. Female SJL/J mice, immunized and boosted with a homogenate of GABHS in Freund's adjuvant, developed immunoreactive antibodies against mouse cerebellum, globus pallidus, and thalamus (Hoffman et al., 2004). Rearing and ambulatory behavioral abnormalities correlated with IgG deposits in deep cerebellar nuclei. This model relates more to mechanisms for GABHS-mediated CNS damage than to either TS or PANDAS (Swerdlow and Sutherland, 2005).

\section{Structural changes in TS \\ Basal ganglia}

Volumetric MRI studies, used to identify neuroanatomical (particularly subcortical) changes in TS, vary extensively. In the largest cohort to date, Peterson et al. (2003) identified a mild but consistent decrease in basal ganglia volume in a cohort of $>150$ TS patients. Subdivided by age, the reduced volume was most apparent in the caudate of children, with adults showing reductions across all basal ganglia re- gions. This finding is supported by a twin study that showed more severely affected siblings to have a smaller right caudate (Hyde et al., 1995) and a longitudinal study demonstrating that caudate volume in childhood varied inversely with tic severity in adulthood (Bloch et al., 2005). In contrast, a study using stricter exclusion criteria to control for confounders failed to demonstrate any changes in caudate volume, but did show increased volume of the putamen bilaterally in TS boys (Roessner et al., 2011). This finding was also identified using an automated image analysis technique capable of assessing differences throughout the brain rather than focusing on specific selected areas (voxelbased morphometry) (Kassubek et al., 2006). Asymmetry of the putamen, without any change in the absolute volumes, has been reported, but results were inconsistent and possibly affected by gender (Singer et al., 1993; Zimmerman et al., 2000). Diffusion tensor imaging (DTI), which measures the movement of water, provides several indices that can reflect microstructural changes. Using this technique, one group has demonstrated microstructural changes in the putamen compared to healthy controls (Makki et al., 2008). These findings were not replicated in a subsequent study, but a correlation was identified between the diffusion parameters and tic severity among TS patients (Neuner et al., 2011).

Neuropathological studies of TS patients are rare, but a few studies have provided evidence of cellular alterations in the basal ganglia to support imaging studies. In a small study (three TS patients and five controls), Kalanithi et al. (2005) found increases in the total number of neurons in the GPi with concomitant decreases in the number and density of neurons in the GPe and caudate. The distribution of parvalbumin-positive GABAergic interneurons was markedly different in TS patients, with a larger percentage residing in the GPi. This same group confirmed their findings in two additional patients and further demonstrated a decrease in striatal cholinergic neurons (Kataoka et al., 2010). Although the results are limited by a small sample size and multiple potential confounders, including possible effects of pharmacologic therapy, it is proposed that these findings strongly implicate the associative and sensorimotor regions of the basal ganglia in the pathogenesis of TS.

\section{Cortex and subcortical white matter}

Significant evidence exists for a primary cortical dysfunction in TS. MRI analyses have detected volumetric changes in the 
cortex of TS patients including larger dorsal prefrontal and parieto-occipital regions, and a smaller inferior occipital region (Peterson et al., 2001). In a limited but well controlled male-only study that excluded medicated patients and those with comorbidities, voxel-based morphometry and magnetization transfer imaging (methods sensitive to tissue alterations and macrostructural integrity) have detected changes in prefrontal, frontal, sensorimotor, and anterior cingulate regions (Müller-Vahl et al., 2009). Using parcellation methods, variable changes have been reported in subcortical white matter, with increases in the right frontal region (Fredericksen et al., 2002) or decreases in left deep frontal white matter (Kates et al., 2002). Cortical thinning has been observed in frontal and parietal lobes, particularly in the sensorimotor cortex; the degree of thinning correlated with tic severity (Sowell et al., 2008). In another study of adults with TS, strength of premonitory sensations correlated with increased sensorimotor cortical volume (Draganski et al., 2010). Other reports evaluating subgroups of TS patients (e.g., those with simple tics, complex tics, and obsessive-compulsive symptoms) found a correlation between the location of cortical thinning and clinical symptoms (Worbe et al., 2010).

Interhemispheric connectivity abnormalities have been suggested by volumetric changes in the corpus callosum (Baumgardner et al., 1996; Mostofsky et al., 1999; Plessen et al., 2004; Cavanna et al., 2010; Roessner et al., 2011), abnormal functional [transcranial magnetic stimulation (TMS)] and structural (DTI) connections between the left and right motor hand areas (Margolis et al., 2006; Plessen et al., 2007; Bäumer et al., 2010), and altered performance on a modified verbal dichotic listening task (Margolis et al., 2006; Plessen et al., 2007; Bäumer et al., 2010) and the bimanual Purdue Pegboard (Margolis et al., 2006; Plessen et al., 2007; Bäumer et al., 2010). Diffusion-weighted imaging has revealed microstructural alterations in the corpus callosum and other white matter (Jackson et al., 2011). Additional support for frontoparietal network abnormalities are based on alterations of MRI resting-state functional connectivity (Church et al., 2009b), tic generation in association with coactivation of the supplementary motor area (Hampson et al., 2009), appearance of secondary tics after resection of the frontal lobe (Yochelson and David, 2000), and investigations on postmortem tissue showing a greater number of biochemical changes in pre- frontal rather than striatal regions (Minzer et al., 2004; Yoon et al., 2007a).

\section{Thalamus}

Structural studies of the thalamus have yielded contradictory results. In two small studies of treatment-naive boys with TS, one found larger left hemithalami (Lee et al., 2005), whereas a second showed bilateral decreases in volume as well as microstructural changes based on alterations in fractional anisotropy using DTI (Makki et al., 2008). A third study, using an automated computational anatomy technique, showed no difference in thalamic size between a small group of TS patients and healthy controls, although this study did not control for numerous variables (Wang et al., 2007). In the largest MRI analysis, including 149 children and adults, there was a $5 \%$ increase in thalamic volume, primarily the lateral thalamus (Miller et al., 2010). Post hoc testing suggested that the differences observed were not due to IQ, treatment history, or comorbid conditions.

\section{Other brain regions}

Several additional brain regions have been implicated in TS. Based on the role of dopamine and known lesions associated with other disorders that involve tics, it was postulated that the midbrain and periaqueductal gray matter might be involved in TS (Devinsky, 1983). This hypothesis is supported by voxel-based morphometry demonstrating increased midbrain gray matter in 31 adult TS patients compared to controls (Garraux et al., 2006). Expanded perivascular spaces in the midbrain, usually considered a benign incidental finding on MRI, have also been correlated with stereotyped behaviors (Dávila et al., 2010). Disruption of corticocerebellar regulatory loops has been postulated based on MRI findings of reduced volumes of the cerebellum, primarily gray matter in crus I and lobules VI, VIIB, and VIIIA (Tobe et al., 2010). Last, altered MRI volumes of the hippocampus and amygdala (Peterson et al., 2007) and DTI diffusion indices (Neuner et al., 2011) has led to suggestions of direct limbic involvement in TS. This hypothesis is supported by hippocampal and amygdala volumes that are larger in pediatric patients and significantly smaller in adult patients with persistent tics (Peterson et al., 2007). The latter suggests a possible failure of normal hippocampal plasticity in the minority of patients whose symptoms persist into adulthood.

\section{Functional changes in TS}

Transcranial magnetic stimulation

One pathogenic mechanism proposed for

TS is decreased inhibitory control of the CSTC circuits. Using TMS to compare 20 adult TS subjects to healthy controls, investigators demonstrated normal motor thresholds but decreased intracortical inhibition and a shortened cortical silent period in TS patients (Ziemann et al., 1997). A similar shortening of the cortical silent period was observed in children with TS, but the changes in intracortical inhibition were not found in this group (Moll et al., 1999). Across a broad age range, the degree of reduction of intracortical inhibition appears to correlate with tic severity (Gilbert et al., 2004).

\section{Functional neuroimaging}

Event-related PET scanning has correlated tic occurrence with activity in a number of brain regions, including the prefrontal cortex, premotor and primary motor cortex, anterior cingulate cortex, putamen, and caudate (Stern et al., 2000). During active tic suppression, there is increased activity in the right frontal cortex and caudate with decreased activity in the globus pallidus, putamen, and thalamus using fMRI (Peterson et al., 1998). Several PET studies have also identified changes in regional blood flow consistent with increased activity in the sensorimotor cortices and decreased activity in the striatum and thalamus (Braun et al., 1993; Eidelberg et al., 1997). A small study using fMRI demonstrated increased activation of the motor cortex during voluntary motor tasks in TS patients, suggesting altered motor organization (Biswal et al., 1998). One study has also shown that tic severity correlated positively with activation of the substantia nigra and ventral tegmentum, lending credence to a dopaminergic role. This same study found that higher tic severity correlated with slower cognitive task performance, independent of comorbid OCD or ADHD symptoms (Baym et al., 2008). In two of the largest fMRI studies, age-related abnormalities in frontostriatal networks and in frontoparietal connectivity were identified, suggesting that TS patients do not undergo normal maturational changes (Marsh et al., 2007; Church et al., 2009a,b). These findings lend support to hypotheses suggesting that TS is a developmental disorder.

\section{Neurotransmitter studies}

Numerous neurotransmitters (dopamine, glutamate, GABA, serotonin, acetylcholine, norepinephrine, and opiates) are involved in the transmission of messages through 
Table 1. Summary of TS studies with notes of methods and limitations

\begin{tabular}{|c|c|c|c|c|}
\hline Reference & Technique & $N(\mathrm{TS})$ & Primary results & Comments \\
\hline \multicolumn{5}{|l|}{ Structural studies } \\
\hline Peterson et al., 2003 & Volumetric MRI & 154 & Reduced caudate volume in TS & Post hoc analyses by age, meds, comorbidity \\
\hline Hyde et al., 1995 & Volumetric MRI & 10 & $\begin{array}{l}\text { Reduced right caudate volume correlated with symptom } \\
\text { severity }\end{array}$ & Twin study; no control for age, treatment, or common comorbidities \\
\hline Bloch et al., 2005 & Volumetric MRI & 43 & $\begin{array}{l}\text { Caudate volume in childhood varies inversely with tic } \\
\text { severity in adulthood }\end{array}$ & $\begin{array}{l}\text { Longitudinal design; includes assessment of OCD but not ADHD } \\
\text { effects; no follow-up imaging }\end{array}$ \\
\hline Roessner et al., 2011 & Volumetric MRI & 49 & Enlarged putamen and corpus callosum in TS & $\begin{array}{l}\text { Children/adolescents only, controlled for age and IQ; exclusion } \\
\text { criteria included prior treatment and comorbid ADHD/OCD }\end{array}$ \\
\hline Kassubek et al., 2006 & Voxel-based morphometry & 14 & Enlarged putamen in TS & $\begin{array}{l}\text { Children only; controlled for age and gender, not treatment; } \\
\text { assessed ADHD but not OCD effects }\end{array}$ \\
\hline Singer et al., 1993 & Volumetric MRI & 37 & $\begin{array}{l}\text { Altered hemispheric asymmetry of putamen and globus } \\
\text { pallidus }\end{array}$ & $\begin{array}{l}\text { Children only; controlled for age; post hoc analysis of ADHD } \\
\text { comorbidity }\end{array}$ \\
\hline $\begin{array}{l}\text { Zimmerman et al., } \\
2000\end{array}$ & Volumetric MRI & 19 & No putamen asymmetry in girls with TS & Controlled for age; assessed for ADHD effect \\
\hline Makki et al., 2008 & Diffusion tensor imaging & 23 & Microstructural abnormalities in thalamus in TS & Controlled for age; no analysis of medication or comorbidity effects \\
\hline Neuner et al., 2011 & Diffusion tensor imaging & 28 & Correlation of BG diffusivity and symptom severity & Adults only; excluded comorbidities \\
\hline Peterson et al., 2007 & Volumetric MRI & 154 & Larger hippocampus and amygdala in TS & Post hoc analyses by age, meds, comorbidity \\
\hline Peterson et al., 2001 & Volumetric MRI & 155 & $\begin{array}{l}\text { Enlarged dorsofrontal and parieto-occipital cortices; } \\
\text { diminished inferior occipital cortex }\end{array}$ & Post hoc analyses by age, meds, comorbidity \\
\hline Müller-Vahl et al., 2009 & Voxel-based morphometry & 19 & $\begin{array}{l}\text { Decreased prefrontal, sensorimotor, anterior cingulate, } \\
\text { and left caudate gray matter; decreased white matter } \\
\text { in right inferior frontal gyrus, left superior frontal } \\
\text { gyrus, and anterior corpus callosum }\end{array}$ & $\begin{array}{l}\text { Adult males only; untreated at least } 1 \text { year; no significant } \\
\text { comorbidities in population }\end{array}$ \\
\hline Müller-Vahl et al., 2009 & $\begin{array}{l}\text { Magnetization transfer } \\
\text { imaging }\end{array}$ & 19 & $\begin{array}{l}\text { White matter reductions in right medial frontal gyrus, } \\
\text { inferior frontal gyrus bilaterally, and right cingulate } \\
\text { gyrus }\end{array}$ & $\begin{array}{l}\text { Adult males only; untreated at least } 1 \text { year; no significant } \\
\text { comorbidities in population }\end{array}$ \\
\hline $\begin{array}{l}\text { Baumgardner et al., } \\
\quad 1996\end{array}$ & Volumetric MRI & 37 & Larger corpus callosum in TS & Children; controlled for age, gender, overall brain volume \\
\hline Mostofsky et al., 1999 & Volumetric MRI & 19 & No difference in corpus callosum & Girls only; assessed effect of ADHD comorbidity \\
\hline Plessen et al., 2004 & Volumetric MRI & 158 & Alterations of corpus callosum, variable with age & Post hoc analyses by age, meds, comorbidity \\
\hline Cavanna et al., 2010 & DTI & 1 & Lower fractional anisotropy of corpus callosum & Twin comparison \\
\hline Draganski et al., 2010 & $\begin{array}{l}\text { Voxel-based morphometry } \\
\text { and DWI }\end{array}$ & 40 & $\begin{array}{l}\text { Cortical thinning diffusely, modulated based on comor- } \\
\text { bidity and symptom severity; increases in primary } \\
\text { somatosensory cortex correlated with premonitory } \\
\text { sensations }\end{array}$ & $\begin{array}{l}\text { Post hoc analysis of comorbidities; infers ongoing structural } \\
\text { plasticity based on a single study }\end{array}$ \\
\hline Jackson et al., 2011 & DWI & 13 & $\begin{array}{l}\text { Diffuse abnormalities in white matter microstructure; } \\
\text { enhanced motor control in TS patients }\end{array}$ & Adults; excluded comorbidities; wide range of tic severity \\
\hline \multicolumn{5}{|l|}{ Functional studies } \\
\hline Ziemann et al., 1997 & $\begin{array}{l}\text { Transcranial magnetic } \\
\text { stimulation }\end{array}$ & 20 & $\begin{array}{l}\text { Shortened cortical silent period and reduced intracortical } \\
\text { inhibition }\end{array}$ & $\begin{array}{l}\text { Adolescent/adult; post hoc analysis by age, sex, comorbidity, and } \\
\text { treatment }\end{array}$ \\
\hline Moll et al., 1999 & $\begin{array}{l}\text { Transcranial magnetic } \\
\text { stimulation }\end{array}$ & 21 & Shortened cortical silent period & Children; post hoc analyses of age, $O C D$, neuroleptic treatment \\
\hline Gilbert et al., 2004 & $\begin{array}{l}\text { Transcranial magnetic } \\
\text { stimulation }\end{array}$ & 36 & $\begin{array}{l}\text { Correlation of cortical disinhibition with tic and ADHD } \\
\text { severity }\end{array}$ & $\begin{array}{l}\text { Children and adults; assessed effects of ADHD and OCD } \\
\text { comorbidities }\end{array}$ \\
\hline Stern et al., 2000 & PET & 6 & $\begin{array}{l}\text { Tic correlation with activity in cortex, putamen, and } \\
\text { caudate }\end{array}$ & Adults; no control for medication; no discussion of comorbidity \\
\hline Peterson et al., 1998 & fMRI & 22 & $\begin{array}{l}\text { Increased cortical activity with decreased striatal and } \\
\text { thalamic activity during active tic suppression }\end{array}$ & Adults; post hoc analyses of gender, treatment, and comorbidity \\
\hline Braun et al., 1993 & PET & 16 & $\begin{array}{l}\text { Increased activity of sensorimotor cortex; reduction of } \\
\text { activity in limbic cortex and striatum }\end{array}$ & Adults; nonmedicated \\
\hline Eidelberg et al., 1997 & PET & 10 & $\begin{array}{l}\text { Increased activity in sensorimotor cortex; decreased in } \\
\text { caudate and thalamus }\end{array}$ & Adults; nonmedicated; no assessment of comorbidity effects \\
\hline Biswal et al., 1998 & fMRI & 5 & $\begin{array}{l}\text { Increased motor cortex activity during voluntary motor } \\
\text { tasks in TS }\end{array}$ & Adults, few from same pedigree; variable severity and comorbidities \\
\hline Church et al., 2009b & fMRI & 33 & Abnormal maturation of functional networks & Adolescents; included comorbidities \\
\hline Marsh et al., 2007 & fMRI & 66 & Abnormal age-related activation of neural circuits & $\begin{array}{l}\text { Adults and children; post hoc analysis of medication and comorbidity } \\
\text { effects }\end{array}$ \\
\hline Baym et al., 2008 & fMRI & 18 & $\begin{array}{l}\text { Tic severity correlated with enhanced activation of dopa- } \\
\text { minergic nuclei and slower response time }\end{array}$ & Children; mostly medication-naive; post hoc analysis of comorbidity; \\
\hline
\end{tabular}


Table 1. Continued

\begin{tabular}{|c|c|c|c|c|}
\hline Reference & Technique & $N(\mathrm{TS})$ & Primary results & Comments \\
\hline \multicolumn{5}{|l|}{ Neurotransmitter studies } \\
\hline Wong et al., 2008 & PET & 16 & Increased phasic dopamine release in ventral striatum & Adults; included assessment of OCD comorbidity \\
\hline Steeves et al., 2010 & PET & 8 & $\begin{array}{l}\text { More widespread phasic dopamine release compared to } \\
\text { controls }\end{array}$ & Adults; controlled for medication exposure and comorbidity \\
\hline Liu et al., 2010 & SPECT & 18 & Higher dopamine transporter expression & Adolescents and adults; drug-naive; no discussion of comorbidities \\
\hline Behen et al., 2007 & PET & 29 & $\begin{array}{l}\text { Abnormal tryptophan metabolism in dorsolateral } \\
\text { prefrontal cortex and thalamus }\end{array}$ & Children; subgroup analyses of medication and comorbidities \\
\hline Haugbøl et al., 2007 & PET & 20 & Increased serotonin receptor binding in TS & Adult; no assessment of medication or comorbidity effects \\
\hline
\end{tabular}

CSTC circuits, and each has been proposed as a potential pathophysiologic mechanism (Singer and Minzer, 2003). Dopamine dysfunction is considered a prime abnormality in TS based on tic suppression with the use of dopamine antagonists (antipsychotics), results from various nuclear imaging protocols (Wolf et al., 1996; Wong et al., 1997, 2008; Singer et al., 2002; Albin et al., 2003; Serra-Mestres et al., 2004; Liu et al., 2010), CSF analysis (Singer et al., 1982), and postmortem studies (Singer et al., 1991, 1995; Minzer et al., 2004; Yoon et al., 2007a). One hypothesis is that either an overactive dopamine transporter or central abnormality leads to an alteration in phasic dopamine release, which in turn, results in a hyperresponsive spike-dependent dopaminergic system (Singer et al., 2004; Wong et al., 2008). This dopaminergic tonic-phasic hypothesis could potentially involve either the cortex or striatum. Although most neurotransmitter-related studies have focused on the striatum, support for an extrastriatal dopaminergic dysfunction includes PET findings of decreased cortical receptor binding potentials and increased dopamine release (Steeves et al., 2010) and postmortem identified cortical dopaminergic abnormalities (Minzer et al., 2004; Yoon et al., 2007a).

Recognizing the various clinical manifestations seen in TS, it is highly likely that this disorder involves a dysfunction of more than one neurotransmitter system or a second messenger defect (Singer and Minzer, 2003). An altered modulatory effect of serotonin in TS has been suggested by the combination of diminished levels of the serotonin transporter and elevated serotonin 2A receptor binding (Wong et al., 2008), as well as PET studies identifying abnormalities of tryptophan metabolism in cortical and subcortical regions (Behen et al., 2007; Haugbøl et al., 2007; Wong et al., 2008). Glutamate has an essential role in pathways involved with CSTC circuits and an extensive interaction with dopaminergic systems (Harris and Singer, 2006). Several lines of evidence support a possible role of the glutamatergic system in TS including results of familial genetic studies (Barr et al., 1999; Tourette Syndrome Association International Consortium for Genetics, 2007; Adamczyk et al., 2010) and reduced levels of glutamate in globus pallidus interna, globus pallidus externa, and substantia nigra pars reticulata in a small number of postmortem brains (Anderson et al., 1992). Altered cholinergic neurotransmission has been implicated by the postmortem finding of decreased numbers of cholinergic interneurons in the striatum of TS patients (Kataoka et al., 2010). Although there is little direct evidence, it has been hypothesized that an alteration of GABAergic projections from the striatum or an impairment of cortical inhibition could cause TS. Last, since multiple neurotransmitters interact with adenosine $3^{\prime}, 5^{\prime}$-monophosphate (cAMP), a postreceptor defect could explain an involvement with multiple transmitter systems. In a small number of postmortem brain samples, the amount of cAMP was reduced in several brain regions (Singer et al., 1991), but a further study showed no abnormality of phosphatidylinositol second messenger generating systems (Singer et al., 1995). In summary, further investigations are required to identify the underlying biochemical defect in this complex disorder.

\section{Limitations and Future Directions}

After decades of extensive research, the pathophysiology underlying TS remains poorly understood. Interpretation of studies is often limited by small sample sizes, incomplete characterization of the subjects, varying ages and clinical severity, concurrent use of pharmacotherapy, and diverse statistical methodologies. Table 1 summarizes the studies discussed in this review, commenting on their methodologies and limitations. Even in the studies containing relatively large numbers of patients, there is often little discussion of how variation in TS symptomatology and related comorbidities relates to the findings. It is certainly possible that simple tics, complex tics, and tic disorders asso- ciated with different comorbidities result from distinctly different underlying pathologies, yet few studies analyze or control for this. Many studies peripherally address the comorbid conditions of ADHD and OCD, but again there have been few studies to adequately and systematically explore the differences between these disorders. Questions also remain regarding the meaning of the neuroanatomical changes observed in TS patients. Although they may be representative of the underlying pathophysiology, they may also be indicative of compensatory changes that have occurred as a result of tics. It would be interesting to study unaffected but at-risk individuals, such as siblings of TS patients, to see whether there are neuroanatomic alterations that exist before the development of tics. As has been suggested in a few studies, developmental or maturational changes are likely important in the pathophysiology, but longitudinal studies exploring changes over time are sparse.

Tourette syndrome provides clinicians, clinician-scientists, and basic researchers with abundant possibilities for future research. On the clinical level, it is essential to further characterize variations in phenotype, understand the relationship between tics and associated comorbidities, clarify factors that modify tic behavior, and continue the search for new and improved behavioral and pharmacologic therapies. Advanced techniques for evaluating the human genome need to be applied to large cohorts with well defined clinical characteristics. The role of the epigenetic modulation requires further attention, both in terms of its ability to potentially modify genetic actions as well as to influence clinical behavior. Clarifying the precise neuroanatomical location and underlying biochemical mechanism would be a major scientific advance not only for TS, but for multiple other neuropsychiatric disorders such as OCD and ADHD. Knowledge of a specific biological alteration will enable the direct pursuit of new ways to treat affected individuals and, dare one say, a possible cure. A highly recommended 
source for additional information on TS is the Tourette Syndrome Association, 42-40 Bell Boulevard, Bayside, NY 11361-2820; telephone 718-224-2999; www.tsa-usa.org.

\section{References}

Adamczyk A, Gause CD, Sattler R, Vidensky S, Rothstein JD, Singer H, Wang T (2010) Genetic and functional studies of a missense variant in a glutamate transporter, SLC1A3, in Tourette syndrome. Psychiatr Genet 21:90-97.

Albin RL, Mink JW (2006) Recent advances in Tourette syndrome research. Trends Neurosci 29:175-182.

Albin RL, Young AB, Penney JB (1989) The functional anatomy of basal ganglia disorders. Trends Neurosci 12:366-375.

Albin RL, Koeppe RA, Bohnen NI, Nichols TE, Meyer P, Wernette K, Minoshima S, Kilbourn MR, Frey KA (2003) Increased ventral striatal monoaminergic innervation in Tourette syndrome. Neurology 61:310-315.

Anderson GM, Pollak ES, Chatterjee D, Leckman JF, Riddle MA, Cohen DJ (1992) Postmortem analysis of subcortical monoamines and amino acids in Tourette syndrome. Adv Neurol 58:123-133.

Barr CL, Wigg KG, Pakstis AJ, Kurlan R, Pauls D, Kidd KK, Tsui LC, Sandor P (1999) Genome scan for linkage to Gilles de la Tourette syndrome. Am J Med Genet 88:437-445.

Bäumer T, Thomalla G, Kroeger J, Jonas M, GerloffC, Hummel FC, Müller-Vahl K, Schnitzler A, Siebner HR, Orth M, Münchau A (2010) Interhemispheric motor networks are abnormal in patients with Gilles de la Tourette syndrome. Mov Disord 25:2828-2837.

Baumgardner TL, Singer HS, Denckla MB, Rubin MA, Abrams MT, Colli MJ, Reiss AL (1996) Corpus callosum morphology in children with Tourette syndrome and attention deficit hyperactivity disorder. Neurology 47:477-482.

Baym CL, Corbett BA, Wright SB, Bunge SA (2008) Neural correlates of tic severity and cognitive control in children with Tourette syndrome. Brain 131:165-179.

Behen M, Chugani HT, Juhász C, Helder E, Ho A, Maqbool M, Rothermel RD, Perry J, Muzik O (2007) Abnormal brain tryptophan metabolism and clinical correlates in Tourette syndrome. Mov Disord 22:2256-2262.

Berridge KC, Aldridge JW, Houchard KR, Zhuang X (2005) Sequential super-stereotypy of an instinctive fixed action pattern in hyperdopaminergic mutant mice: a model of obsessive compulsive disorder and Tourette's. BMC Biol 3:4.

Biswal B, Ulmer JL, Krippendorf RL, Harsch HH, Daniels DL, Hyde JS, Haughton VM (1998) Abnormal cerebral activation associated with a motor task in Tourette syndrome. AJNR Am J Neuroradiol 19:1509-1512.

Bloch MH, Leckman JF, Zhu H, Peterson BS (2005) Caudate volumes in childhood predict symptom severity in adults with Tourette syndrome. Neurology 65:1253-1258.

Bloch MH, Peterson BS, Scahill L, Otka J, Katsovich L, Zhang H, Leckman JF (2006) Adulthood outcome of tic and obsessive-compulsive symptom severity in children with Tourette syndrome. Arch Pediatr Adolesc Med 160:65-69.

Braun AR, Stoetter B, Randolph C, Hsiao JK, Vla- dar K, Gernert J, Carson RE, Herscovitch P, Chase TN (1993) The functional neuroanatomy of Tourette's syndrome: an FDG-PET study. I. Regional changes in cerebral glucose metabolism differentiating patients and controls. Neuropsychopharmacology 9:277-291.

Burd L, Severud R, Klug MG, Kerbeshian J (1999) Prenatal and perinatal risk factors for Tourette disorder. J Perinat Med 27:295-302.

Burton FH, Hasel KW, Bloom FE, Sutcliffe JG (1991) Pituitary hyperplasia and gigantism in mice caused by a cholera toxin transgene. $\mathrm{Na}$ ture 350:74-77.

Campbell KM, Veldman MB, McGrath MJ, Burton FH (2000) TS+OCD-like neuropotentiated mice are supersensitive to seizure induction. Neuroreport 11:2335-2338.

Canales JJ, Graybiel AM (2000) A measure of striatal function predicts motor stereotypy. Nat Neurosci 3:377-383.

Cavanna AE, Eddy C, Rickards HE (2009) Cognitive functioning in Tourette syndrome. Discov Med 8:191-195.

Cavanna AE, Stecco A, Rickards H, Servo S, Terazzi E, Peterson B, Robertson MM, Carriero A, Monaco F (2010) Corpus callosum abnormalities in Tourette syndrome: an MRI-DTI study of monozygotic twins. J Neurol Neurosurg Psychiatry 81:533-535.

Channon S, Pratt P, Robertson MM (2003) Executive function, memory, and learning in Tourette's syndrome. Neuropsychology 17:247-254

Church JA, Wenger KK, Dosenbach NU, Miezin FM, Petersen SE, Schlaggar BL (2009a) Task control signals in pediatric Tourette syndrome show evidence of immature and anomalous functional activity. Front Hum Neurosci 3:38.

Church JA, Fair DA, Dosenbach NU, Cohen AL, Miezin FM, Petersen SE, Schlaggar BL (2009b) Control networks in paediatric Tourette syndrome show immature and anomalous patterns of functional connectivity. Brain 132:225-238.

Crane J, Fagerness J, Osiecki L, Gunnell B, Stewart SE, Pauls DL, Scharf JM (2011) Familybased genetic association study of DLGAP3 in Tourette Syndrome. Am J Med Genet B Neuropsychiatr Genet 156B:108-114.

Dávila G, Berthier ML, Kulisevsky J, Asenjo B, Gómez J, Lara JP, Chacón SJ, Campos VM (2010) Structural abnormalities in the substantia nigra and neighbouring nuclei in Tourette's syndrome. J Neural Transm 117:481-488.

Devinsky O (1983) Neuroanatomy of Gilles de la Tourette's syndrome. Possible midbrain involvement. Arch Neurol 40:508-514.

Dodman NH, Normile JA, Shuster L, Rand W (1994) Equine self-mutilation syndrome (57 cases). J Am Vet Med Assoc 204:1219-1223.

Draganski B, Martino D, Cavanna AE, Hutton C, Orth $\mathrm{M}$, Robertson MM, Critchley HD, Frackowiak RS (2010) Multispectral brain morphometry in Tourette syndrome persisting into adulthood. Brain 133:3661-3675.

Eapen V, O’Neill J, Gurling HM, Robertson MM (1997) Sex of parent transmission effect in Tourette's syndrome: evidence for earlier age at onset in maternally transmitted cases suggests a genomic imprinting effect. Neurology 48:934-937.

Eidelberg D, Moeller JR, Antonini A, Kazumata K,
Dhawan V, Budman C, Feigin A (1997) The metabolic anatomy of Tourette's syndrome. Neurology 48:927-934.

Ercan-Sencicek AG, Stillman AA, Ghosh AK, Bilguvar $\mathrm{K}$, O’Roak BJ, Mason CE, Abbott $\mathrm{T}$, Gupta A, King RA, Pauls DL, Tischfield JA, Heiman GA, Singer HS, Gilbert DL, Hoekstra PJ, Morgan TM, Loring E, Yasuno K, Fernandez T, Sanders S, et al. (2010) L-histidine decarboxylase and Tourette's syndrome. N Engl J Med 362:1901-1908.

Fredericksen KA, Cutting LE, Kates WR, Mostofsky SH, Singer HS, Cooper KL, Lanham DC, Denckla MB, Kaufmann WE (2002) Disproportionate increases of white matter in right frontal lobe in Tourette syndrome. Neurology 58:85-89.

Garraux G, Goldfine A, Bohlhalter S, Lerner A, Hanakawa T, Hallett M (2006) Increased midbrain gray matter in Tourette's syndrome. Ann Neurol 59:381-385.

Gilbert DL, Batterson JR, Sethuraman G, Sallee FR (2004) Tic reduction with risperidone versus pimozide in a randomized, doubleblind, crossover trial. J Am Acad Child Adolesc Psychiatry 43:206-214.

Goetz CG, Klawans HL (1982) Gilles de la Tourette on Tourette syndrome. Adv Neurol 35:1-16.

Grados MA (2010) The genetics of obsessivecompulsive disorder and Tourette syndrome: an epidemiological and pathway-based approach for gene discovery. J Am Acad Child Adolesc Psychiatry 49:810-819, 819.e1-2.

Graybiel AM (2000) The basal ganglia. Curr Biol 10:R509-511.

Hallett JJ, Harling-Berg CJ, Knopf PM, Stopa EG, Kiessling LS (2000) Anti-striatal antibodies in Tourette syndrome cause neuronal dysfunction. J Neuroimmunol 111:195-202.

Hampson M, Tokoglu F, King RA, Constable RT, Leckman JF (2009) Brain areas coactivating with motor cortex during chronic motor tics and intentional movements. Biol Psychiatry 65:594-599.

Hanna PA, Janjua FN, Contant CF, Jankovic J (1999) Bilineal transmission in Tourette syndrome. Neurology 53:813-818.

Harris K, Singer HS (2006) Tic disorders: neural circuits, neurochemistry, and neuroimmunology. J Child Neurol 21:678-689.

Haugbøl S, Pinborg LH, Regeur L, Hansen ES, Bolwig TG, Nielsen FA, Svarer C, Skovgaard LT, Knudsen GM (2007) Cerebral 5-HT2A receptor binding is increased in patients with Tourette's syndrome. Int J Neuropsychopharmacol 10:245-252.

Hoffman KL, Hornig M, Yaddanapudi K, Jabado O, Lipkin WI (2004) A murine model for neuropsychiatric disorders associated with group A $\beta$-hemolytic streptococcal infection. J Neurosci 24:1780-1791.

Hyde TM, Aaronson BA, Randolph C, Rickler KC, Weinberger DR (1992) Relationship of birth weight to the phenotypic expression of Gilles de la Tourette's syndrome in monozygotic twins. Neurology 42:652-658.

Hyde TM, Stacey ME, Coppola R, Handel SF, Rickler KC, Weinberger DR (1995) Cerebral morphometric abnormalities in Tourette's syndrome: a quantitative MRI study of monozygotic twins. Neurology 45:1176-1182. 
Jackson SR, Parkinson A, Jung J, Ryan SE, Morgan PS, Hollis C, Jackson GM (2011) Compensatory neural reorganization in Tourette syndrome. Curr Biol 21:580-585.

Kalanithi PS, Zheng W, Kataoka Y, DiFiglia M, Grantz H, Saper CB, Schwartz ML, Leckman JF, Vaccarino FM (2005) Altered parvalbuminpositive neuron distribution in basal ganglia of individuals with Tourette syndrome. Proc Natl Acad Sci U S A 102:13307-13312.

Kassubek J, Juengling FD, Ludolph AG (2006) Heterogeneity of voxel-based morphometry findings in Tourette's syndrome: an effect of age? Ann Neurol 59:872-873.

Kataoka Y, Kalanithi PS, Grantz H, Schwartz ML, Saper C, Leckman JF, Vaccarino FM (2010) Decreased number of parvalbumin and cholinergic interneurons in the striatum of individuals with Tourette syndrome. J Comp Neurol 518:277-291.

Kates WR, Frederikse M, Mostofsky SH, Folley BS, Cooper K, Mazur-Hopkins P, Kofman O, Singer HS, Denckla MB, Pearlson GD, Kaufmann WE (2002) MRI parcellation of the frontal lobe in boys with attention deficit hyperactivity disorder or Tourette syndrome. Psychiatry Res 116:63-81.

Kurlan R (1998) Tourette's syndrome and 'PANDAS': will the relation bear out? Pediatric autoimmune neuropsychiatric disorders associated with streptococcal infection. Neurology 50:1530-1534.

Kurlan R (2004) The PANDAS hypothesis: losing its bite? Mov Disord 19:371-374.

Kurlan R (2010) Clinical practice. Tourette's Syndrome. N Engl J Med 363:2332-2338.

Kurlan R, Kaplan EL (2004) The pediatric autoimmune neuropsychiatric disorders associated with streptococcal infection (PANDAS) etiology for tics and obsessive-compulsive symptoms: hypothesis or entity? Practical considerations for the clinician. Pediatrics 113:883-886.

Kurlan R, McDermott MP, Deeley C, Como PG, Brower C, Eapen S, Andresen EM, Miller B (2001) Prevalence of tics in schoolchildren and association with placement in special education. Neurology 57:1383-1388.

Kurlan R, Johnson D, Kaplan EL (2008) Streptococcal infection and exacerbations of childhood tics and obsessive-compulsive symptoms: a prospective blinded cohort study. Pediatrics 121:1188-1197.

Leckman JF, Dolnansky ES, Hardin MT, Clubb M, Walkup JT, Stevenson J, Pauls DL (1990) Perinatal factors in the expression of Tourette's syndrome: an exploratory study. J Am Acad Child Adolesc Psychiatry 29:220-226.

Leckman JF, Zhang H, Vitale A, Lahnin F, Lynch K, Bondi C, Kim YS, Peterson BS (1998) Course of tic severity in Tourette syndrome: the first two decades. Pediatrics 102:14-19.

Leckman JF, Bloch MH, Smith ME, Larabi D, Hampson M (2010) Neurobiological substrates of Tourette's disorder. J Child Adolesc Psychopharmacol 20:237-247.

Leckman JF, King RA, Gilbert DL, Coffey BJ, Singer HS, Dure LS 4th, Grantz H, Katsovich L, Lin H, Lombroso PJ, Kawikova I, Johnson DR, Kurlan RM, Kaplan EL (2011) Streptococcal upper respiratory tract infections and exacerbations of tic and obsessive-compulsive symptoms: a pro- spective longitudinal study. J Am Acad Child Adolesc Psychiatry 50:108-118.e3.

Lee CC, Chou IC, Tsai CH, Wang TR, Li TC, Tsai FJ (2005) Dopamine receptor D2 gene polymorphisms are associated in Taiwanese children with Tourette syndrome. Pediatr Neurol 33:272-276.

Lichter DG, Jackson LA, Schachter M (1995) Clinical evidence of genomic imprinting in Tourette's syndrome. Neurology 45:924-928.

Lichter DG, Dmochowski J, Jackson LA, Trinidad KS (1999) Influence of family history on clinical expression of Tourette's syndrome. Neurology 52:308-316.

Liu H, Dong F, Meng Z, Zhang B, Tan J, Wang Y (2010) Evaluation of Tourette's syndrome by (99m)Tc-TRODAT-1 SPECT/CT imaging. Ann Nucl Med 24:515-521.

Liu X, Wang Y, Li D, Ju X (2008) Transplantation of rat neural stem cells reduces stereotypic behaviors in rats after intrastriatal microinfusion of Tourette syndrome sera. Behav Brain Res 186:84-90.

Loiselle CR, Lee O, Moran TH, Singer HS (2004) Striatal microinfusion of Tourette syndrome and PANDAS sera: Failure to induce behavioral changes. Mov Disord 19:390-396.

Löscher W (2010) Abnormal circling behavior in rat mutants and its relevance to model specific brain dysfunctions. Neurosci Biobehav Rev 34:31-49.

Makki MI, Behen M, Bhatt A, Wilson B, Chugani HT (2008) Microstructural abnormalities of striatum and thalamus in children with Tourette syndrome. Mov Disord 23:2349-2356.

Margolis A, Donkervoort M, Kinsbourne M, Peterson BS (2006) Interhemispheric connectivity and executive functioning in adults with Tourette syndrome. Neuropsychology 20:66-76.

Marsh R, Zhu H, Wang Z, Skudlarski P, Peterson BS (2007) A developmental fMRI study of selfregulatory control in Tourette's syndrome. Am J Psychiatry 164:955-966.

Mathews CA, Bimson B, Lowe TL, Herrera LD, Budman CL, Erenberg G, Naarden A, Bruun RD, Freimer NB, Reus VI (2006) Association between maternal smoking and increased symptom severity in Tourette's syndrome. Am J Psychiatry 163:1066-1073.

Mazzone L, Yu S, Blair C, Gunter BC, Wang Z, Marsh R, Peterson BS (2010) An FMRI study of frontostriatal circuits during the inhibition of eye blinking in persons with Tourette syndrome. Am J Psychiatry 167:341-349.

McCairn KW, Bronfeld M, Belelovsky K, Bar-Gad I (2009) The neurophysiological correlates of motor tics following focal striatal disinhibition. Brain 132:2125-2138.

McMahon WM, Carter AS, Fredine N, Pauls DL (2003) Children at familial risk for Tourette's disorder: Child and parent diagnoses. Am J Med Genet 121B:105-111.

Miller AM, Bansal R, Hao X, Sanchez-Pena JP, Sobel LJ, Liu J, Xu D, Zhu H, Chakravarty MM, Durkin K, Ivanov I, Plessen KJ, Kellendonk CB, Peterson BS (2010) Enlargement of thalamic nuclei in Tourette syndrome. Arch Gen Psychiatry 67:955-964.

Mink JW (2001) Basal ganglia dysfunction in Tourette's syndrome: a new hypothesis. Pediatr Neurol 25:190-198.
Mink JW (2003) The basal ganglia and involuntary movements: impaired inhibition of competing motor patterns. Arch Neurol 60:1365-1368.

Minzer K, Lee O, Hong JJ, Singer HS (2004) Increased prefrontal D2 protein in Tourette syndrome: a postmortem analysis of frontal cortex and striatum. J Neurol Sci 219:55-61.

Moll GH, Wischer S, Heinrich H, Tergau F, Paulus W, Rothenberger A (1999) Deficient motor control in children with tic disorder: evidence from transcranial magnetic stimulation. Neurosci Lett 272:37-40.

Morris CM, Pardo-Villamizar C, Gause CD, Singer HS (2009) Serum autoantibodies measured by immunofluorescence confirm a failure to differentiate PANDAS and Tourette syndrome from controls. J Neurol Sci 276:45-48.

Mostofsky SH, Wendlandt J, Cutting L, Denckla MB, Singer HS (1999) Corpus callosum measurements in girls with Tourette syndrome. Neurology 53:1345-1347.

Müller-Vahl KR, Kaufmann J, Grosskreutz J, Dengler R, Emrich HM, Peschel T (2009) Prefrontal and anterior cingulate cortex abnormalities in Tourette Syndrome: evidence from voxelbased morphometry and magnetization transfer imaging. BMC Neurosci 10:47.

Murphy TK, Kurlan R, Leckman J (2010) The immunobiology of Tourette's disorder, pediatric autoimmune neuropsychiatric disorders associated with Streptococcus, and related disorders: a way forward. J Child Adolesc Psychopharmacol 20:317-331.

Neuner I, Kupriyanova Y, Stöcker T, Huang R, Posnansky O, Schneider F, Shah NJ (2011) Microstructure assessment of grey matter nuclei in adult Tourette patients by diffusion tensor imaging. Neurosci Lett 487:22-26.

Nordstrom EJ, Burton FH (2002) A transgenic model of comorbid Tourette's syndrome and obsessive-compulsive disorder circuitry. Mol Psychiatry 7:617-625, 524.

O’Rourke JA, Scharf JM, Yu D, Pauls DL (2009) The genetics of Tourette syndrome: a review. J Psychosom Res 67:533-545.

Pauls DL (2006) A genome-wide scan and fine mapping in Tourette syndrome families. Adv Neurol 99:130-135.

Peterson BS, Skudlarski P, Anderson AW, Zhang H, Gatenby JC, Lacadie CM, Leckman JF, Gore JC (1998) A functional magnetic resonance imaging study of tic suppression in Tourette syndrome. Arch Gen Psychiatry 55:326-333.

Peterson BS, Staib L, Scahill L, Zhang H, Anderson C, Leckman JF, Cohen DJ, Gore JC, Albert J, Webster R (2001) Regional brain and ventricular volumes in Tourette syndrome. Arch Gen Psychiatry 58:427-440.

Peterson BS, Thomas P, Kane MJ, Scahill L, Zhang $\mathrm{H}$, Bronen R, King RA, Leckman JF, Staib L (2003) Basal ganglia volumes in patients with Gilles de la Tourette syndrome. Arch Gen Psychiatry 60:415-424.

Peterson BS, Choi HA, Hao X, Amat JA, Zhu H Whiteman R, Liu J, Xu D, Bansal R (2007) Morphologic features of the amygdala and hippocampus in children and adults with Tourette syndrome. Arch Gen Psychiatry 64:1281-1291.

Plessen KJ, Wentzel-Larsen T, Hugdahl K, Feineigle P, Klein J, Staib LH, Leckman JF, Bansal R, Peterson BS (2004) Altered interhemispheric 
connectivity in individuals with Tourette's disorder. Am J Psychiatry 161:2028-2037.

Plessen KJ, Lundervold A, Grüner R, Hammar A, Lundervold A, Peterson BS, Hugdahl K (2007) Functional brain asymmetry, attentional modulation, and interhemispheric transfer in boys with Tourette syndrome. Neuropsychologia 45:767-774.

Price RA, Kidd KK, Cohen DJ, Pauls DL, Leckman JF (1985) A twin study of Tourette syndrome. Arch Gen Psychiatry 42:815-820.

Pringsheim T, Lang A, Kurlan R, Pearce M, Sandor P (2009) Understanding disability in Tourette syndrome. Dev Med Child Neurol 51:468-472.

Roessner V, Overlack S, Schmidt-Samoa C, Baudewig J, Dechent P, Rothenberger A, Helms G (2011) Increased putamen and callosal motor subregion in treatment-naïve boys with Tourette syndrome indicates changes in the bihemispheric motor network. J Child Psychol Psychiatry 52:306-314.

Scharf JM, Moorjani P, Fagerness J, Platko JV, Illmann C, Galloway B, Jenike E, Stewart SE, Pauls DL (2008) Lack of association between SLITRK1var321 and Tourette syndrome in a large family-based sample. Neurology 70 : 1495-1496.

Serra-Mestres J, Ring HA, Costa DC, Gacinovic S, Walker Z, Lees AJ, Robertson MM, Trimble MR (2004) Dopamine transporter binding in Gilles de la Tourette syndrome: a [123I]FPCIT/SPECT study. Acta Psychiatr Scand 109: 140-146.

Singer HS, Harris K (2006) Circuits to synapses: The pathophysiology of Tourette syndrome. In: Neurobiology of disease, Ed 1 (Gilman S, ed). Burlington, MA: Elsevier Academic.

Singer HS, Loiselle C (2003) PANDAS: a commentary. J Psychosom Res 55:31-39.

Singer HS, Minzer K (2003) Neurobiology of Tourette syndrome: concepts of neuroanatomical localization and neurochemical abnormalities. Brain Dev 25 [Suppl]:S70-S84.

Singer HS, Tune LE, Butler IJ, Zaczek R, Coyle JT (1982) Clinical symptomatology, CSF neurotransmitter metabolites, and serum haloperidol levels in Tourette syndrome. Adv Neurol 35:177-183.

Singer HS, Hahn IH, Moran TH (1991) Abnormal dopamine uptake sites in postmortem striatum from patients with Tourette's syndrome. Ann Neurol 30:558-562.

Singer HS, Reiss AL, Brown JE, Aylward EH, Shih B, Chee E, Harris EL, Reader MJ, Chase GA, Bryan RN, Denckla MB (1993) Volumetric MRI changes in basal ganglia of children with Tourette's syndrome. Neurology 43:950-956.

Singer HS, Dickson J, Martinie D, Levine M (1995) Second messenger systems in Tourette's syndrome. J Neurol Sci 128:78-83.

Singer HS, Szymanski S, Giuliano J, Yokoi F, Dogan AS, Brasic JR, Zhou Y, Grace AA, Wong DF (2002) Elevated intrasynaptic dopamine release in Tourette's syndrome measured by PET. Am J Psychiatry 159:1329-1336.

Singer HS, Hong JJ, Rippel CA, Pardo CA (2004) The need for caution in considering the diagnostic utility of antibasal ganglia antibodies in movement disorders. Arch Dis Child 89:595-597.

Singer HS, Mink JW, Loiselle CR, Burke KA, Ruch- kina I, Morshed S, Parveen S, Leckman JF, Hallett JJ, Lombroso PJ (2005a) Microinfusion of antineuronal antibodies into rodent striatum: failure to differentiate between elevated and low titers. J Neuroimmunol 163:8-14.

Singer HS, Hong JJ, Yoon DY, Williams PN (2005b) Serum autoantibodies do not differentiate PANDAS and Tourette syndrome from controls. Neurology 65:1701-1707.

Singer HS, Gause C, Morris C, Lopez P (2008) Serial immune markers do not correlate with clinical exacerbations in pediatric autoimmune neuropsychiatric disorders associated with streptococcal infections. Pediatrics 121: $1198-1205$.

Singer HS, Morris C, Grados M (2010) Glutamatergic modulatory therapy for Tourette syndrome. Med Hypotheses 74:862-867.

Snider LA, Swedo SE (2003) Post-streptococcal autoimmune disorders of the central nervous system. Curr Opin Neurol 16:359-365.

Sowell ER, Kan E, Yoshii J, Thompson PM, Bansal $\mathrm{R}$, Xu D, Toga AW, Peterson BS (2008) Thinning of sensorimotor cortices in children with Tourette syndrome. Nat Neurosci 11: 637-639.

State MW (2010) The genetics of child psychiatric disorders: focus on autism and Tourette syndrome. Neuron 68:254-269.

Steeves TD, Ko JH, Kideckel DM, Rusjan P, Houle S, Sandor P, Lang AE, Strafella AP (2010) Extrastriatal dopaminergic dysfunction in Tourette syndrome. Ann Neurol 67:170-181.

Stern E, Silbersweig DA, Chee KY, Holmes A, Robertson MM, Trimble M, Frith CD, Frackowiak RS, Dolan RJ (2000) A functional neuroanatomy of tics in Tourette syndrome. Arch Gen Psychiatry 57:741-748.

Sukhodolsky DG, Scahill L, Zhang H, Peterson BS, King RA, Lombroso PJ, Katsovich L, Findley D, Leckman JF (2003) Disruptive behavior in children with Tourette's syndrome: association with ADHD comorbidity, tic severity, and functional impairment. J Am Acad Child Adolesc Psychiatry 42:98-105.

Swedo SE, Leonard HL, Garvey M, Mittleman B, Allen AJ, Perlmutter S, Lougee L, Dow S, Zamkoff J, Dubbert BK (1998) Pediatric autoimmune neuropsychiatric disorders associated with streptococcal infections: clinical description of the first 50 cases. Am J Psychiatry 155:264-271.

Swerdlow NR, Sutherland AN (2005) Using animal models to develop therapeutics for Tourette Syndrome. Pharmacol Ther 108:281-293.

Taylor JL, Rajbhandari AK, Berridge KC, Aldridge JW (2010) Dopamine receptor modulation of repetitive grooming actions in the rat: potential relevance for Tourette syndrome. Brain Res 1322:92-101.

Taylor JR, Morshed SA, Parveen S, Mercadante MT, Scahill L, Peterson BS, King RA, Leckman JF, Lombroso PJ (2002) An animal model of Tourette's syndrome. Am J Psychiatry 159: 657-660.

Tobe RH, Bansal R, Xu D, Hao X, Liu J, Sanchez J, Peterson BS (2010) Cerebellar morphology in Tourette syndrome and obsessive-compulsive disorder. Ann Neurol 67:479-487.

Tourette Syndrome Association International
Consortium for Genetics (2007) Genome scan for Tourette disorder in affected-siblingpair and multigenerational families. Am J Hum Genet 80:265-272.

Wang WF, Lei YP, Tseng T, Hsu WY, Wang CF, Hsu CC, Ho YJ (2007) Effects of apomorphine on the expression of learned helplessness behavior. Chin J Physiol 50:63-68.

Wolf SS, Jones DW, Knable MB, Gorey JG, Lee KS, Hyde TM, Coppola R, Weinberger DR (1996) Tourette syndrome: prediction of phenotypic variation in monozygotic twins by caudate nucleus D2 receptor binding. Science 273:1225-1227.

Wong DF, Singer HS, Brandt J, Shaya E, Chen C, Brown J, Kimball AW, Gjedde A, Dannals RF, Ravert HT, Wilson PD, Wagner HN Jr (1997) D2-like dopamine receptor density in Tourette syndrome measured by PET. J Nucl Med 38: 1243-1247.

Wong DF, Brasić JR, Singer HS, Schretlen DJ, Kuwabara H, Zhou Y, Nandi A, Maris MA, Alexander M, Ye W, Rousset O, Kumar A, Szabo Z, Gjedde A, Grace AA (2008) Mechanisms of dopaminergic and serotonergic neurotransmission in Tourette syndrome: clues from an in vivo neurochemistry study with PET. Neuropsychopharmacology 33:1239-1251.

Worbe Y, Gerardin E, Hartmann A, Valabrégue R, Chupin M, Tremblay L, Vidailhet M, Colliot O, Lehéricy S (2010) Distinct structural changes underpin clinical phenotypes in patients with Gilles de la Tourette syndrome. Brain 133:3649-3660.

Yochelson MR, David RG (2000) New-onset tic disorder following acute hemorrhage of an arteriovenous malformation. J Child Neurol 15:769-771.

Yoon DY, Gause CD, Leckman JF, Singer HS (2007a) Frontal dopaminergic abnormality in Tourette syndrome: a postmortem analysis. J Neurol Sci 255:50-56.

Yoon DY, Rippel CA, Kobets AJ, Morris CM, Lee JE, Williams PN, Bridges DD, Vandenbergh DJ, Shugart YY, Singer HS (2007b) Dopaminergic polymorphisms in Tourette syndrome: association with the DAT gene (SLC6A3). Am J Med Genet B Neuropsychiatr Genet 144B:605-610.

Young HA, Geier DA, Geier MR (2008) Thimerosal exposure in infants and neurodevelopmental disorders: an assessment of computerized medical records in the Vaccine Safety Datalink. J Neurol Sci 271:110-118.

Zhuang X, Oosting RS, Jones SR, Gainetdinov RR, Miller GW, Caron MG, Hen R (2001) Hyperactivity and impaired response habituation in hyperdopaminergic mice. Proc Natl Acad Sci U S A 98:1982-1987.

Ziemann U, Paulus W, Rothenberger A (1997) Decreased motor inhibition in Tourette's disorder: evidence from transcranial magnetic stimulation. Am J Psychiatry 154:1277-1284.

Zimmerman AM, Abrams MT, Giuliano JD, Denckla MB, Singer HS (2000) Subcortical volumes in girls with Tourette syndrome: support for a gender effect. Neurology 54:22242229. 